\title{
RFLP markers associated with major genes controlling heading date evaluated in a barley germ plasm pool
}

\author{
ERNESTO IGARTUA $\dagger$, ANA M. CASAS*†, FRANCISCO CIUDAD \\ JOSÉ L. MONTOYA \& \& IGNACIO ROMAGOSA§ \\ $\dagger$ Department of Genetics and Plant Production, Estación Experimental de Aula Dei, CSIC, PO Box 202, 50080-Zaragoza, \\ Spain; $₫$ Servicio de Investigación Agraria, Junta de Castilla y León, PO Box 172, 47080-Valladolid, Spain and \\ §Universitat de Lleida-Institut de Recerca i Tecnologia Agroalimentàries, Av. Rovira Roure 177, 25196-Lleida, Spain
}

\begin{abstract}
Adjustment of crop phenology to resources and constraints of the production environment is crucial for barley adaptation to dry-land environments. The aims of this study were to characterize (under field and under controlled conditions) the diverse heading responses of barley cultivars grown in Spain, and to identify phenotypic trait-molecular marker associations with restriction fragment length polymorphism (RFLP) probes which are linked to major loci controlling vernalization ( $S h$ and $\mathrm{Sh}_{2}$ ) and photoperiod ( $\mathrm{Ppd}-\mathrm{H} 1$ and $\mathrm{Ppd}-\mathrm{H2}$ ) sensitivities in barley. Thirty-two cultivars were sown in field trials for 3 years in four locations in northern Spain (10 autumn and nine winter sowings), and for 1 year in southern Spain (autumn sowing), and 2 years in Scotland (spring sowings); they were also studied under four glasshouse treatments, combining presence/absence of vernalization and short/long photoperiod. These cultivars were examined for the presence of RFLP polymorphisms with four probes and three restriction enzymes. Analyses of variance detected a number of associations which were quite consistent with expectations, suggesting that marker-loci associations found in mapping populations are, to some extent, maintained in a germ plasm pool, and may be useful for germ plasm characterization and marker-assisted selection in breeding programmes. Two possible epistatic interactions among the probes were detected, one of them possibly related to a short-day vernalization response.
\end{abstract}

Keywords: barley, photoperiod, RFLP variation, vernalization.

\section{Introduction}

Adjustment of crop phenology to resources and constraints of the production environment is crucial in determining adaptation of barley to dry-land environments (Roberts et al., 1988; Ellis et al., 1989), even more so under Mediterranean conditions (van Oosterom \& Acevedo, 1992). Heading time in barley is controlled by three constituent characters, namely vernalization requirement, photoperiod sensitivity and earliness per se (Takahashi \& Yasuda, 1970). Three genes, Sh, $S h_{2}$ and $S h_{3}$, located on chromosomes $4(4 \mathrm{H}), 7(5 \mathrm{H})$ and 5 $(1 \mathrm{H})$, respectively, are responsible for winter/spring

Correspondence: Ana M. Casas, Department of Genetics and Plant Production, Estación Experimental de Aula Dei, CSIC, PO Box 202, 50080-Zaragoza, Spain. Tel.: + 34 976576511. Fax: + 34976575620 . E-mail: acasas@eead.csic.es

*Correspondence. E-mail: acasas@eead.csic.es

(C) 1999 The Genetical Society of Great Britain. growth habit and vernalization response. Recently, using restriction fragment length polymorphism (RFLP) markers, Laurie et al. $(1994,1995)$ identified five major genes and eight quantitative trait loci (QTL) controlling flowering time in a winter $\times$ spring barley cross. These included two photoperiod response genes, $\mathrm{Ppd}-\mathrm{HI}$ and Ppd-H2 on chromosomes $2(2 \mathrm{H})$ and $5(1 \mathrm{H})$, respectively, and two vernalization genes coincident with the positions of $S h$ and $S h_{2}$. Therefore, three genes, $S h, S h_{2}$ and $S h_{3}$, seem to control the vernalization requirements of barley, and two genes, $\mathrm{Ppd}-\mathrm{HI}$ and $\mathrm{Ppd}-\mathrm{H} 2$, seem responsible for the photoperiod response, although $S h_{3}$ has been found to segregate only in barleys from extremely low or high latitudes (Takahashi \& Yasuda, 1970).

One issue of paramount interest to breeders is the extrapolation of the information provided by studies carried out in segregating populations to the range of germ plasm available in breeding programmes. If this were possible, a further step towards predicting the 


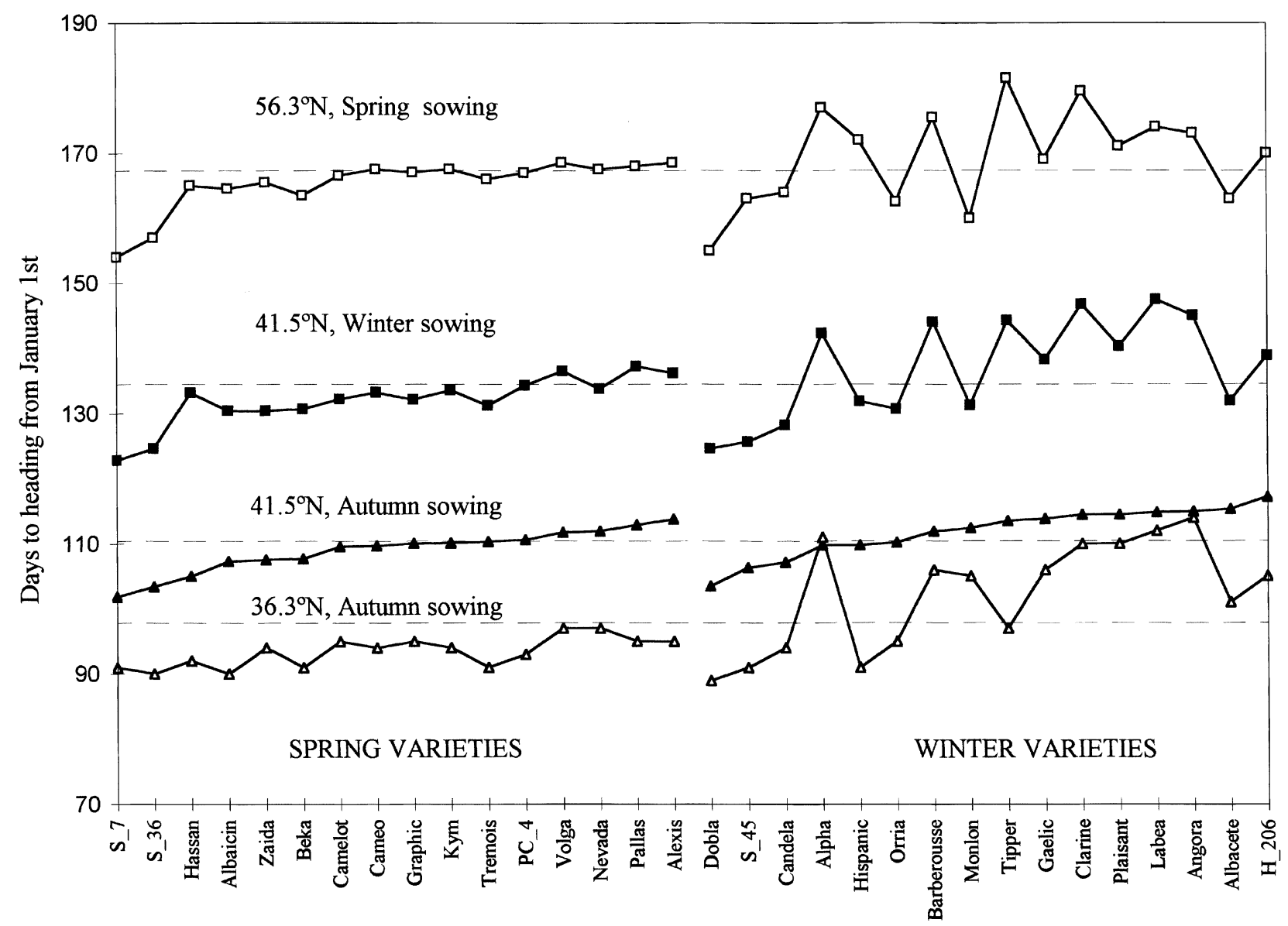

Fig. 1 Mean heading dates for 32 barley cultivars in four sets of field trials.

potential of crosses in a breeding programme and trying to implement marker-assisted selection, would come from knowledge on genetic constitution of parents (cultivars or other type of materials) at major loci controlling traits of agronomic interest.

This report is part of a larger study aimed at defining adaptation patterns of barley to Spanish conditions. The objectives of this study were: (i) to obtain a thorough phenotypic assessment of heading date for a group of barley cultivars; (ii) to determine the genetic constitution for four markers linked to loci controlling heading date; and (iii) to assess the predictive value of those markers on sensitivities of cultivars to vernalization and photoperiod.

\section{Materials and methods}

\section{Field trials}

Thirty-two barley cultivars representative of the barley types grown in northern Spain were used for this study
(Fig. 1). The materials were quite diverse, including 2- and 6-rowed types, malt and feed types, and with geographical origins from all over Europe (except for three ICARDA* genotypes). Half of the cultivars were winter types, and the other half were spring types, according to the Spanish Official Registry of Commercial Varieties (MAPA, 1997), and also according to breeders' experience of their agronomic adaptation. The complete list and description of cultivars was given in Casas et al. (1998).

A total of 19 (10 autumn sown and nine winter sown) field trials were carried out at four provinces in northern Spain (Lleida, Navarra, Valladolid and Zaragoza), for three seasons (1995-97). These trials can be considered as a representative sample of barley growing environments in northern Spain. Additional trial crops were grown at Dundee (Scotland), in 1994-95 and 1995-96, and at Cádiz (southern Spain) in 1995-96, to expose the cultivars to contrasting environments, outside the range of variation normally encountered in northern Spain.

*International Center for Agricultural Research in the Dry Areas (ICARDA), Aleppo, Syria

(c) The Genetical Society of Great Britain, Heredity, 83, 551-559. 
All experiments followed a randomized complete block design, with three replicates. Plots consisted of six or eight rows, $6 \mathrm{~m}$ long, and between 1.2 and $1.5 \mathrm{~m}$ wide, depending on locations. Crop husbandry followed local practices at each location.

Heading date was taken as the day when approximately $2 \mathrm{~cm}$ of awns were visible in $50 \%$ of stems. Mean heading dates for cultivars were then calculated across sowing dates in northern Spain experiments. These averages were named $41.5^{\circ} \mathrm{N}$, autumn sowing and $41.5^{\circ} \mathrm{N}$, winter sowing, respectively, after the average latitude of the trials (which was quite similar for the four northern provinces). These averages are representative of heading date of barley cultivars across northern Spain, for the two typical sowing dates in the region. Accordingly, the Dundee and Cádiz experiments were also named after the latitude of the sites $\left(56.3^{\circ} \mathrm{N}\right.$, spring sowing and $36.3^{\circ} \mathrm{N}$, autumn sowing, respectively).

\section{Glasshouse experiments}

The same 32 cultivars tested in field trials were tested in 1998 under controlled conditions in four experiments, combining presence or absence of vernalization with long or short photoperiod. These treatments were coded as VLP (vernalization followed by long photoperiod), NVLP (no vernalization, long photoperiod), VSP (vernalization, short photoperiod) and NVSP (no vernalization, short photoperiod). The treatments were applied as follows: eight plants per cultivar were vernalized for 8 weeks in a growth chamber $\left(12 / 4^{\circ} \mathrm{C}\right.$ day/night temperatures, $9 \mathrm{~h}$ light). When the vernalization period was completed, four plants per cultivar were transferred to glasshouses with daylength set to $17 \mathrm{~h}$ (long photoperiod) or $12 \mathrm{~h}$ (short photoperiod), and temperature to $20 / 10^{\circ} \mathrm{C}$ (day/night). Two weeks before the end of the vernalization period, another four seeds per cultivar were sown in pots, directly in the long and short photoperiod glasshouses. By the end of the vernalization period, both vernalized and unvernalized plants reached approximately the same developmental stage. The plants were grown in $11 \times 11 \mathrm{~cm}$ pots, which were placed on large glasshouse tables. Four plants (one plant per pot) were tested for each cultivar-treatment combination. Thermal time (accumulated temperature, taking $0^{\circ} \mathrm{C}$ as base temperature) from seedling emergence until flag leaf unfolding was recorded for each plant. Vernalization requirement (VER) for each cultivar was estimated as the accumulated thermal time until flag leaf unfolding in the NVLP treatment, minus thermal time in the VLP treatment. Photoperiod sensitivity (PHO) was calculated as the corresponding difference in accumulated thermal time between the VSP and VLP treatments.

\section{RFLP analysis}

Four RFLP probes were used to analyse polymorphism at the molecular level, for all the cultivars. Probes were selected because they map in regions close to major genes affecting heading date. The probes were Bmyl (linked to $S h)$ on chromosome $4(4 \mathrm{H})$; CDO504 $\left(\mathrm{Sh}_{2}\right)$ on $7(5 \mathrm{H})$; MWG858 (Ppd-HI) on $2(2 \mathrm{H})$; and MWG518 $(P p d-H 2)$ on $5(1 \mathrm{H})$. The barley mapping populations used to identify these markers were: two winter $\times$ spring crosses, namely Igri $\times$ Triumph (Laurie et al., 1995), and Dicktoo $\times$ Morex (Pan et al., 1994); one winter $\times$ winter cross, Igri $\times$ Danilo (Backes et al., 1995); and three spring $\times$ spring crosses, namely Blenheim $\times$ Kym (Bezant et al., 1996), Steptoe $\times$ Morex (Hayes et al., 1993) and Harrington $\times$ TR306 (Tinker et al., 1996). Another set of RFLP probes was also analysed. These probes (designated as 'blank' probes) were selected because they are located in chromosomal regions which never appeared associated with heading date in the studies cited above. The study of their association with our phenotypic data will provide a tool for quantifying type I error levels expected in the analysis (i.e. declaring a significant effect when it does not exist). The probes were: ABC455, ABG704 and MWG003 on chromosome 1 (7H); ABG058 and MWG865 on chr. $2(2 \mathrm{H})$; MWG584 on chr. $3(3 \mathrm{H})$; MWG058 and MWG634 on chr. 4 (4H); ABC261, MWG800 and MWG938 on chr. $5(1 \mathrm{H})$; ABC309 and CDO749 on chr. $7(5 \mathrm{H})$.

Probes (clones) were analysed in combination with three restriction enzymes (BamHI, Eco RI, and HindIII). One clone-enzyme combination (CEC) was selected for each probe, based on band pattern simplicity and strength of relationship with phenotypic variables. An RFLP pattern was defined as the combination of all bands occurring in a lane for a given CEC-cultivar combination. From here on we use the terms 'allele' and 'banding pattern' as synonyms for practical purposes, although the allelic relationship of the banding patterns for a particular CEC cannot be proven from this study. Analyses of variance for the patterns presented by each CEC were performed, for all phenotypic traits. Additionally, twoway factorial analyses of variance were carried out for pairs of CECs. All analyses were carried out according to standard SAS/STAT procedures (SAS Institute, 1989).

\section{Results}

The cultivars exhibited a wide variety of heading responses both in field (Fig. 1) and glasshouse trials 
Table 1 Descriptive statistics for traits recorded in the glasshouse treatments (thermal time from emergence to flag leaf unfolding) for 32 barley varieties

\begin{tabular}{lcrrrr}
\hline Variable & Photoperiod at heading & Mean & SD & Min. & Max. \\
\hline Vernalization-long photoperiod (VLP) & $17 \mathrm{~h}$ & 1315 & 177 & 936 & 1762 \\
Unvernalized-long photoperiod (NVLP) & $17 \mathrm{~h}$ & 1512 & 543 & 547 & 2467 \\
Vernalization-short photoperiod (VSP) & $12 \mathrm{~h}$ & 1413 & 230 & 968 & 1841 \\
Unvernalized-short photoperiod (NVSP) & $12 \mathrm{~h}$ & 1813 & 440 & 917 & 2717 \\
Photoperiod effect in vernalized plants (PHO) & & 98 & 139 & -74 & 435 \\
Vernalization effect under long photoperiod (VER) & & 198 & 427 & -460 & 953 \\
\hline
\end{tabular}

(Table 1). The range of variation in the $41.5^{\circ} \mathrm{N}$ autumn sowing trials was narrower (15.3 days) than in other trials (24.8-27.5 days), suggesting that, overall, conditions at the $41.5^{\circ} \mathrm{N}$ autumn sowing trials were the most favourable to induce heading. Regarding vernalization, it is obvious that trials sown in autumn at $41.5^{\circ} \mathrm{N}$ experienced more days at low temperature than trials sown in winter. An indication of the extent of vernalization received by the cultivars in each group of trials is the number of days with mean temperature below $8^{\circ} \mathrm{C}$. This value was 12 and 75 days for the autumn-sown trials $\left(36.3^{\circ} \mathrm{N}\right.$ and $41.5^{\circ} \mathrm{N}$, respectively), 21 for the $41.5^{\circ} \mathrm{N}$ winter-sown trials, and seven days for the $56.3^{\circ} \mathrm{N}$ trials. It is likely that $41.5^{\circ} \mathrm{N}$ winter sowings, $56.3^{\circ} \mathrm{N}$ spring sowings, and the $36.3^{\circ} \mathrm{N}$ autumn sowing probably lacked sufficient cold days to fulfil the vernalization requirement of most winter cultivars. At these three series of trials, heading of the most winter cultivars was markedly delayed. At $56.3^{\circ} \mathrm{N}$, this delay occurred even for the winter cultivar Hispanic. This is an early cultivar which requires a small amount of vernalization. This requirement was probably met at the other series of trials, but not at Dundee.

Figure 1 presents the average heading dates for all cultivars in the four series of field experiments. Cultivars are listed according to their heading date at the $41.5^{\circ} \mathrm{N}$ autumn-sowing trials. The cultivars were separated into spring and winter types following traditional classifications. Heading dates for spring cultivars showed small variations across trials. Heading dates for the winter cultivars fluctuated more, probably depending on the environmental cues faced at each series of trials. The most winter-like cultivars (according to official recommendations, and authors' experience), namely Angora, Labea, Plaisant, Clarine, Tipper, Barberousse and Alpha, suffered marked heading delays at the $41.5^{\circ} \mathrm{N}$ winter-sowing and $56.3^{\circ} \mathrm{N}$ spring-sowing trials, most probably because of lack of vernalization.

A summary of the results from the glasshouse treatments is presented in Table 1. Thermal time until flag leaf unfolding was minimum for the a priori most inductive treatment (vernalization followed by long photoperiod), and increased under any other conditions. The standard deviation for this variable was also minimal at the VLP treatment, i.e. cultivars were less variable at the most heading-inductive treatment, as observed for the field trials.

Linear correlation coefficients between thermal time until flag leaf unfolding in the four glasshouse treatments and field trial heading dates were all significant (Table 2). This fact suggests that there was a large influence of earliness per se factors on the determination of heading date in this set of materials. In other words, the genotypic variation for earliness per se is quite large. Also presented in Table 2 are the correlation coefficients between field heading dates and the vernalization (VER) and photoperiod (PHO) effects estimated from the glasshouse treatments. The correlation of heading time with PHO decreased as the number of days under long photoperiod in the field trials increased, becoming

Table 2 Linear correlation coefficients for barley varieties between heading dates at the four series of field trials, and variables measured in the glasshouse experiments: accumulated thermal time from emergence until flag leaf unfolding for four treatments, and the vernalization and photoperiod effects (for column headings, see Table 1)

\begin{tabular}{lcccccc}
\hline Variables & VLP & VSP & NVLP & NVSP & PHO & VER \\
\hline Heading date $36.3^{\circ} \mathrm{N}$, autumn sowing & $0.71^{* * *}$ & $0.87^{* * *}$ & $0.65^{* * *}$ & $0.86^{* * *}$ & $0.53^{* * *}$ & $0.56^{* * * *}$ \\
Heading date $41.5^{\circ} \mathrm{N}$, autumn sowing & $0.57^{* * *}$ & $0.66^{* * *}$ & $0.55^{* * *}$ & $0.72^{* * *}$ & $0.36^{* *}$ & $0.47^{* * *}$ \\
Heading date $41.5^{\circ} \mathrm{N}$, winter sowing & $0.81^{* * *}$ & $0.77^{* * *}$ & $0.83^{* * *}$ & $0.87^{* * *}$ & 0.24 & $0.72^{* * *}$ \\
Heading date $56.3^{\circ} \mathrm{N}$, spring sowing & $0.78^{* * *}$ & $0.65^{* * *}$ & $0.86^{* * *}$ & $0.79^{* * *}$ & 0.08 & $0.77^{* * *}$ \\
\hline
\end{tabular}

Correlation coefficient significant at $* P<0.05, * * P<0.01$, ${ }^{* * *} P<0.001$. 
nonsignificant for the winter- and spring-sown trials. All correlation coefficients with VER were significant, suggesting that the vernalization requirements of all cultivars were not fully met at any series of field trials (i.e. cultivars requiring vernalization were generally later at all trials). But the trend observed for these coefficients was consistent with expectations, and with climatic data, as the lowest coefficient corresponded to the $41.5^{\circ} \mathrm{N}$ autumn-sowing trials, where more cold days occurred. Under these conditions, the vernalization requirements of winter cultivars were at least partially met, and heading dates were only slightly later than spring cultivars. The same could be said for the VLP treatment, in which there were no significant differences among cultivars.

A summary of the polymorphisms found for the four probes linked to major genes controlling vernalization requirement (Bmy1, CDO504) or photoperiod sensitivity (MWG858, MWG518) is given in Table 3. We found polymorphism for all four probes so that more than one banding pattern was present for each CEC. Only two or three banding patterns were found (Table 3), but for MWG858 (with any enzyme) there was an uncommon and a frequent allele. With MWG858-EcoRI, it is interesting to note that 30 varieties presented the same pattern, whereas the only two cultivars of Spanish landrace origin (Albacete and H-206) were different (allele $B$ ). These cultivars had significantly later heading dates than the rest at the $41.5^{\circ} \mathrm{N}$ autumn sowing (Fig. 1 and Table 3), but became relatively earlier at trials heading later in the year (under longer photoperiod). In the glasshouse treatments, differences in PHO between groups were also significant.

The results for MWG518 (Table 3) were significant only for the two series of field trials where heading occurred under shorter photoperiod $\left(36.3^{\circ} \mathrm{N}\right.$ and $41.5^{\circ} \mathrm{N}$ autumn sowing, as shown in Fig. 1). Significant differences among allelic means also occurred for the two glasshouse experiments with short photoperiod, and for photoperiod sensitivity (PHO). Interestingly, allelic means were not significantly different for vernalization requirement (VER).

Bmyl results were also quite consistent with expectations. This probe, with HindIII, produced almost distinct groups of winter/spring type cultivars (Casas et al., 1998). Allele $A$ was typical of spring barleys, whereas allele $B$ was present in most winter types. There were significant differences among groups of cultivars at the $36.3^{\circ} \mathrm{N}$ autumn-sowing trial (where the number of cold days was low), for three glasshouse treatments (including the two which did not receive vernalization), and for both effects, VER and PHO.

CDO504, close to $S h_{2}$, did not seem to be associated with heading date, or thermal time until flag leaf unfolding at any of the field or glasshouse treatments.
However, the differences between CDO504 groups for VER and PHO were both significant (Table 3).

The results of the analyses for the 'blank' probes detected 14 significant $(P<0.05)$ associations, which is $10.8 \%$ of the 130 associations tested (13 probes with the 10 variables presented in Table 3). This is not much greater than the expected $5 \%$ of spurious associations for the chosen level of probability, especially if we take into account that the phenotypic variables were correlated. This means that any spurious RFLP-variable association had a high chance of being significant for other phenotypic variables. In fact, three of the 'blank' probes accounted for nine of the 14 significant associations found. From the effects described in the literature for $\mathrm{Sh}, \mathrm{Sh}_{2}, \mathrm{Ppd}-\mathrm{H} 1$ and $\mathrm{Ppd}-\mathrm{H} 2$, we deduced which associations might have been significant for the four probes presented in Table 3. These associations totalled 22, and are underlined in Table 3. In this study, 11 of the 22 expected associations were significant. This $50 \%$ association is much greater than the $10.8 \%$ found for the 'blank' probes.

The combined analyses of variance for pairs of CECs produced some significant interactions (Table 3), i.e. in some cases, the linear model including the interaction of the two CECs explained significantly more variation than was expected from the sum of the additive effects of both CECs. This indicates epistasis. As the photoperiod at flowering time increased, the interaction factor Bmy $1 \times$ CDO504 became larger, and was significant for the $56.3^{\circ} \mathrm{N}$ spring-sowing trials. This interaction is represented in Fig. 2, and seemed mostly caused by the behaviour of cultivars with $A / B$ and $B / B$ (Bmyl/ CDO504) banding patterns. This interaction was also significant for the four glasshouse treatments (Table 3).

Another significant interaction occurred for Bmy $1 \times$ MWG518 at the $36.3^{\circ} \mathrm{N}$ autumn-sowing field trial, where four cultivars presenting the $B$ pattern of Bmyl (which probably indicates winter type), actually reached heading as early as the spring cultivars ( $A$ pattern of Bmy1). This behaviour suggested a short-day vernalization response, as described by Roberts et al. (1988). This is a phenomenon observed in some cultivars which partly replace their vernalization requirement when exposed to short photoperiod. This type of response was confirmed by the glasshouse experiments for two of the cultivars involved (Tipper and Hispanic), which reached flag leaf at the NVSP treatment earlier than at the NVLP treatment.

\section{Discussion}

We have found results quite consistent with theory for the four probes located close to major genes controlling vernalization and photoperiod sensitivities (Table 3). 
Table 3 Means of barley varieties grouped according to banding patterns for the four RFLP probes linked to major genes governing heading date in barley. Where the differences among groups were significant (according to an analysis of variance), a pairwise $t$-test comparison was performed. The last two columns show the significance of the $F$-test for the interaction term when analyses of variance for paired clone-enzyme combinations (CECs) were performed.

Underlined are the cases where allelic means are expected to be different based on previous studies using mapping populations

\begin{tabular}{|c|c|c|c|c|c|c|c|c|c|c|c|c|}
\hline \multirow[b]{2}{*}{ Variable } & \multicolumn{3}{|c|}{ Bmy1 } & \multicolumn{3}{|c|}{ CDO504 } & \multicolumn{2}{|c|}{ MWG858 } & \multicolumn{2}{|c|}{ MWG518 } & \multirow{2}{*}{$\begin{array}{l}\text { Bmy1 } \times \\
\text { CDO504 }\end{array}$} & \multirow{2}{*}{$\begin{array}{l}\text { Bmy1 } \times \\
\text { MWG518 }\end{array}$} \\
\hline & A $(14) \dagger$ & B (15) & C (3) & A (11) & B (11) & C (10) & A (30) & B (2) & A (22) & B (10) & & \\
\hline Field trials & \multicolumn{6}{|c|}{ Days to heading from 1 January } & & & & & \multicolumn{2}{|c|}{$F$-test significance $\S$} \\
\hline $\begin{array}{l}\text { Heading date } 36.3^{\circ} \mathrm{N}, \\
\text { autumn sowing }\end{array}$ & $\underline{93.6 \div \mathrm{b}}$ & $101.3 \mathrm{a}$ & $\underline{100.3 \mathrm{a}}$ & $\underline{98.6}$ & $\underline{99.2}$ & $\underline{95.5}$ & 97.5 & 103.0 & $\underline{99.9 \mathrm{a}}$ & $\underline{93.3 \mathrm{~b}}$ & 0.638 & 0.011 \\
\hline $\begin{array}{l}\text { Heading date } 41.5^{\circ} \mathrm{N}, \\
\text { autumn sowing }\end{array}$ & 109.1 & 110.9 & 114.2 & 110.8 & 110.0 & 110.4 & $110.0 \mathrm{~b}$ & $116.2 \mathrm{a}$ & $111.1 \mathrm{a}$ & $\underline{108.8 \mathrm{~b}}$ & 0.105 & 0.159 \\
\hline $\begin{array}{l}\text { Heading date } 41.5^{\circ} \mathrm{N}, \\
\text { winter sowing }\end{array}$ & $\underline{131.8}$ & $\underline{137.1}$ & $\underline{133.8}$ & $\underline{135.4}$ & $\underline{134.6}$ & $\underline{133.3}$ & $\underline{134.4}$ & $\underline{135.4}$ & 135.3 & 132.8 & 0.064 & 0.411 \\
\hline $\begin{array}{l}\text { Heading date } 56.3^{\circ} \mathrm{N}, \\
\text { spring sowing }\end{array}$ & $\underline{165.0}$ & $\underline{169.8}$ & $\underline{165.2}$ & $\underline{167.1}$ & $\underline{167.9}$ & $\underline{166.8}$ & $\underline{167.3}$ & $\underline{166.5}$ & 167.8 & 166.2 & 0.007 & 0.941 \\
\hline Glasshouse experiment & \multicolumn{6}{|c|}{ Accumulated thermal time $\left({ }^{\circ} \mathrm{C}\right)$, emergence-flag leaf unfolding } & & & & & \multicolumn{2}{|c|}{$F$-test significance } \\
\hline $\begin{array}{l}\text { Vernalization-long } \\
\text { photoperiod, VLP }\end{array}$ & 1271 & 1361 & 1286 & 1314 & 1313 & 1316 & $\underline{1320}$ & $\underline{1240}$ & 1350 & 1236 & 0.029 & 0.856 \\
\hline $\begin{array}{l}\text { Vernalization-short } \\
\text { photoperiod, VSP }\end{array}$ & $1274 \mathrm{~b}$ & $1510 \mathrm{a}$ & $1571 \mathrm{a}$ & 1387 & 1506 & 1338 & 1400 & 1600 & $\underline{1483 \mathrm{a}}$ & $\underline{1257 \mathrm{~b}}$ & 0.050 & 0.568 \\
\hline $\begin{array}{l}\text { No vernal.-long } \\
\text { photoperiod, NVLP }\end{array}$ & $\underline{1172 \mathrm{~b}}$ & $\underline{1795 \mathrm{a}}$ & $\underline{1685 \mathrm{a}}$ & $\underline{1515}$ & $\underline{1750}$ & $\underline{1249}$ & $\underline{1495}$ & $\underline{1771}$ & 1599 & 1322 & 0.014 & 0.926 \\
\hline $\begin{array}{l}\text { No vernal.-short } \\
\text { photoperiod, NVSP }\end{array}$ & $\underline{1522 \mathrm{~b}}$ & $\underline{2027 \mathrm{a}}$ & $\underline{2153 \mathrm{a}}$ & $\underline{1839}$ & $\underline{1922}$ & $\underline{1663}$ & 1790 & 2153 & $\underline{1915 \mathrm{a}}$ & $\underline{1587 \mathrm{~b}}$ & 0.042 & 0.465 \\
\hline $\begin{array}{l}\text { Photoperiod effect } \\
\text { (vernal. plants), PHO }\end{array}$ & $3 \mathrm{~b}$ & $149 \mathrm{a}$ & $285 \mathrm{a}$ & $73 \mathrm{~b}$ & $193 \mathrm{a}$ & $21 \mathrm{~b}$ & $\underline{81 \mathrm{~b}}$ & $\underline{359 \mathrm{a}}$ & $\underline{133 \mathrm{a}}$ & $\underline{21 \mathrm{~b}}$ & 0.740 & 0.473 \\
\hline $\begin{array}{l}\text { Vernal. effect (under } \\
\text { long phot.), VER }\end{array}$ & $-\underline{99 \mathrm{~b}}$ & $\underline{434 \mathrm{a}}$ & $\underline{399 \mathrm{a}}$ & $\underline{200 \mathrm{ab}}$ & $\underline{436 \mathrm{a}}$ & $-68 \mathrm{~b}$ & 175 & 531 & 249 & 86 & 0.038 & 0.832 \\
\hline
\end{tabular}

$†$ Each capital letter designates a banding pattern; in parentheses the number of cultivars with that banding pattern.

tMeans followed by the same letter, within probes, are not significantly different at $P<0.05$.

$\S$ Significance of the $F$-test for the interaction between probes in the analyses of variance. 
Fig. 2 Plots of interaction in barley varieties between heading dates (field) or accumulated thermal time $\left({ }^{\circ} \mathrm{C}\right)$ from emergence until flag leaf unfolding (glasshouse) and RFLP band patterns, for Bmy1/CDO504, and Bmy1/MWG518 probe combinations. Bars represent $\pm 1 \mathrm{SE}$ of the mean.
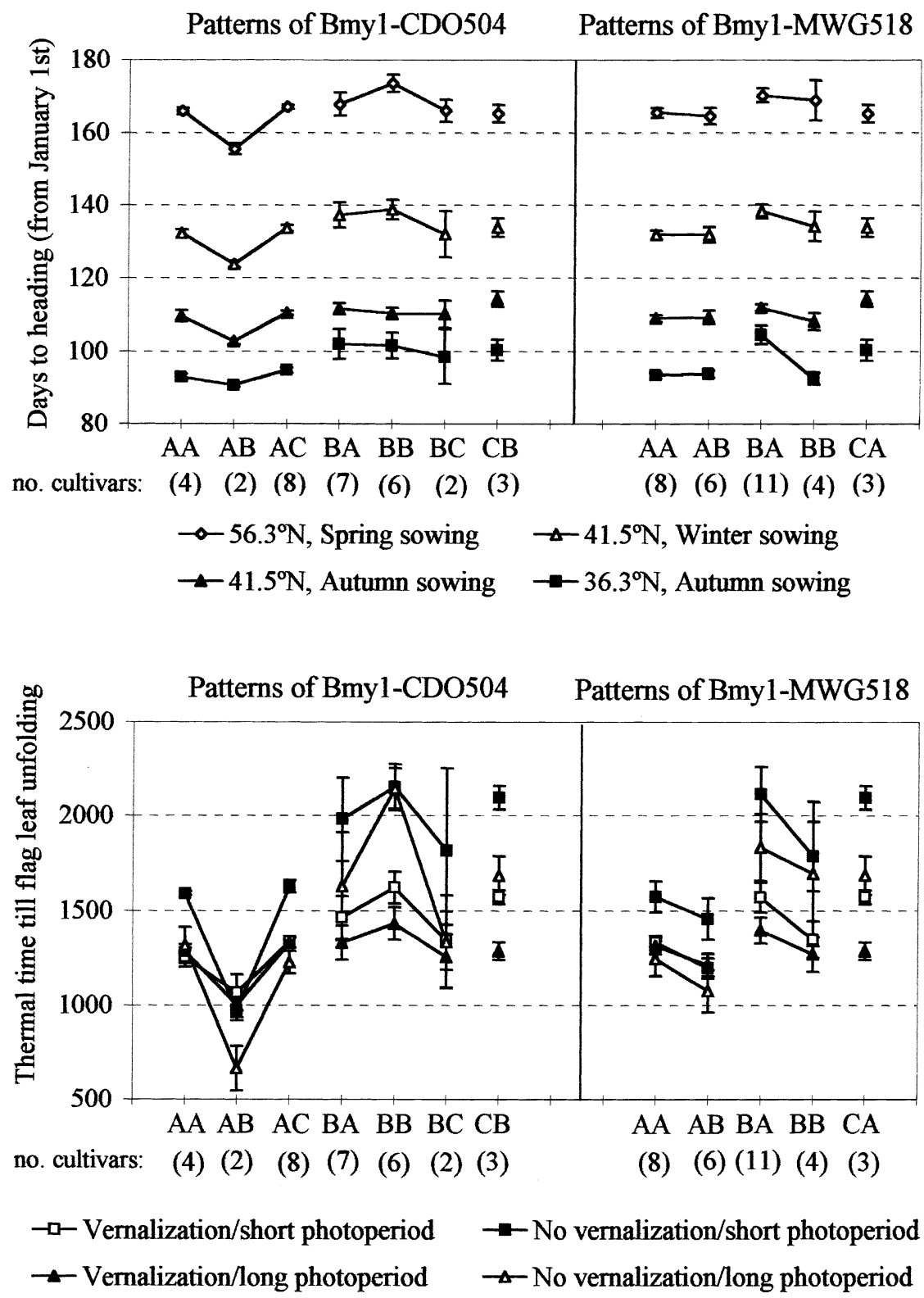

For Bmy1, there were differences (4.8-7.7 days) between the spring $(A)$ and the winter $(B)$ allele for the three series of field trials which experienced fewer cold days, although that difference was significant only for the $36.3^{\circ} \mathrm{N}$ trials (Table 3). In contrast, the difference between the two alleles at the $41.5^{\circ} \mathrm{N}$ autumn-sowing trials was just 1.8 days. For CDO504, however, associations were in general weaker than for Bmyl. Most studies have found relatively small effects of $S h$ and $S h_{2}$ on field heading dates (Hayes et al., 1993; Laurie et al., 1995; Bezant et al., 1996; Tinker et al., 1996), whereas their effect under controlled conditions was much larger (Pan et al., 1994; Karsai et al., 1997). In our study, the differences between allelic means for the probes close to vernalization genes were also more evident in glasshouse than in field trials.

For the probes located near photoperiod genes, one presented significant association with heading date in earlier-sown field trials, and short photoperiod glasshouse treatments (MWG518). This behaviour is consistent with the findings of Laurie et al. (1995), who identified a locus (Ppd-H2) whose effect on heading date was evident only under short photoperiod.

The other probe reportedly close to a photoperiod gene (MWG858) appeared associated with photoperiod sensitivity measured in the glasshouse, and with one of the field trials under shorter photoperiod (Table 3). This behaviour suggests a certain photoperiod sensitivity 
specific to the cultivars of Spanish landrace origin. Laurie et al. (1994) detected polymorphism for MWG 858 in the cross Igri $\times$ Triumph, which was associated with a major photoperiod sensitivity locus, whose effects were evident under long photoperiod. However, the polymorphism found by Laurie et al. (1994) for this probe was probably detected with a different enzyme (probably DraI or EcoRV, although it was not specified). We examined the RFLP patterns of the parents of their mapping population (Igri and Triumph), and found no polymorphism for MWG858 with any of our three enzymes. As the Ppd-H1 region in chromosome 2 $(2 \mathrm{H})$ is clearly involved in photoperiod response of barley (Hayes et al., 1993; Backes et al., 1995; Laurie et al., 1995; Bezant et al., 1996; Karsai et al., 1997), and we have found very low polymorphism level for MWG858 in our materials, it is likely that we have not been able to account for a considerable part of photoperiod response in this study. It was encouraging, however, to find a banding pattern for the same probe (allele $B$ ), which belonged to cultivars presenting a marked photoperiod sensitivity, and that this allele seemed different from previously described variants in the literature.

Some possible epistatic interactions are shown in Table 3 and Fig. 2. One of these interactions, Bmy1 $\times$ MWG518, might be explained as a short-day vernalization response. Laurie et al. (1995) also found a short-day vernalization response in two dihaploid lines from the Igri $\times$ Triumph cross. They deduced that this response was caused by the presence of a Triumph allele of $\mathrm{Ppd}-\mathrm{H} 2$ in an otherwise winter (Igri) genotype. This explanation (plus other details provided by the authors) is totally consistent with the interaction found by us. The interaction observed is caused by the very different heading dates of $B / A$ and $B / B$ (Bmyl/MWG518) patterns at the $36.3^{\circ} \mathrm{N}$ trial (Fig. 2). The combination $B / B$ would be the genetic pattern potentially associated with short-day vernalization, and corresponds to the Igri-like (winter) pattern for Bmyl (close to Sh), and to the Triumph-like pattern of MWG518 (close to $P p d-H 2$ ). Interactions between major genes governing vernalization and photoperiod responses are not new. Karsai et al. (1997) found a possible interaction for heading date between $P p d$ in chromosome 2 (probably $P p d-H I)$ and $S h_{2}$ in a Dicktoo $\times$ Morex dihaploid population. They found that a combination of both loci explained above $90 \%$ of phenotypic variation for heading date, significantly more than the sum of individual effects for each locus.

The other interaction found in this study, Bmy $1 \times$ CDO504, provides further evidence of an epistatic relationship between $S h$ and $S h_{2}$. This interaction was first described by Takahashi \& Yasuda (1970). It also has a possible correspondence with previous work by Laurie et al. (1995), who found that the Igri allele of $S h$ acted as a strong enhancer of the $S h_{2}$ vernalization response in Igri $\times$ Triumph. It was not possible to confirm whether the interaction found in our study is similar to theirs, as we did not find polymorphism between Igri and Triumph for CDO504 (data not shown). In order to test the potential epistatic interactions found in this study, a population of dihaploid lines has been developed from a Beka $\times$ Mogador cross.

Studies of association between molecular or biochemical markers and phenotypic traits in germ plasm pools (elite lines, cultivars, germ plasm bank accessions) have been carried out for several crops. These include BarHen et al. (1995) in maize, Virk et al. (1996) in rice, Beer et al. (1997) in oat, Pakniyat et al. (1997) in Hordeum spontaneum, and Paull et al. (1998) in wheat. In all cases, significant and potentially useful marker-phenotypic trait associations were found. It must be noted, however, that these associations are not necessarily a consequence of linkage, and most authors argue against drawing this conclusion. Bar-Hen et al. (1995) observed that some associations between genetic markers in collections of inbred lines were generated by linkage disequilibrium, which were not only a result of markers' chromosomal location but, rather, depended on general breeding history of the germ plasm. These linkage disequilibria might be caused by founder effects, and by differential selection for adaptedness among breeding groups. This is the type of association that we may have found for the 'blank' probes (besides true type I error cases). Marker-phenotypic trait associations found in this study for the four selected probes are probably true and meaningful, as the existence of major genes in these regions has been repeatedly reported in the literature. Thus, it can be said that these associations found in several populations are, to some extent, maintained in a germ plasm pool, and that these associations do not result from chance. Therefore, it would not be unrealistic to complement the search for useful markerphenotypic trait associations in mapping populations with a confirmation of the existence of the association in germ plasm pools, at least for genes with major effects. At present, it seems possible to use Bmyl and MWG518, at least, for preliminary screening of germ plasm in breeding programmes.

\section{Acknowledgements}

We appreciate the collaboration of the following people and institutions: J. S. Swanston (Scottish Crop Research Institute, Invergowrie, UK), J. A. Conde (Complejo Asgrow, S. A., Spain), J. Voltás (ETSIA Lleida), A. Lafarga (ITGA Navarra, Pamplona) and M. P.

(c) The Genetical Society of Great Britain, Heredity, 83, 551-559. 
Gracia (EEAD-CSIC, Zaragoza), for providing field data from Scotland, Cádiz, Lleida, Navarra and Zaragoza, respectively; A. Kleinhofs, A. Graner and M. Sorrells for kindly providing the probes used in this study; R. B. Austin for useful discussions; and the CICYT (Comisión Interministerial de Ciencia y Tecnología) for funding this research (projects AGF95-1008C05 and AGF98-0251-C03).

\section{References}

BACKeS, G., GRANER, A., FOROUGHI-WEHR, B., FISCHBECK, G., WENZEL, G. AND JAHOOR, A. 1995. Localization of quantitative trait loci (QTL) for agronomic important characters by the use of a RFLP map in barley (Hordeum vulgare L.). Theor. Appl. Genet., 90, 294-302.

BAR-HEN, A., CHARCosSet, A., BOURGoIN, M. AND GUIARD, J. 1995. Relationship between genetic markers and morphological traits in a maize inbred lines collection. Euphytica, 84, 145-154.

BEER, S. C., SIRIPOONWIWAT, W., O'DONOUGHUE, L. S., SOUZA, E., MATTHEWS, D. AND SORRELLS, M. E. 1997. Associations between molecular markers and quantitative traits in an oat germplasm pool: Can we infer linkages? J. Agric. Genomics, 3, Article 1 http://probenalusdagov:8000/ otherdocs/jag.

BeZANT, J., LAURIE, D., PRATCHETT, N., CHOJECKI, J. AND KEARSEY, M. 1996. Marker regression mapping of QTL controlling flowering time and plant height in a spring barley (Hordeum vulgare L.) cross. Heredity, 77, 64-73.

CASAS, A. M., IGARTUA, E., VALlÉS, M. P. AND MOLINA-CANO, J. L. 1998. Genetic diversity of barley cultivars grown in Spain estimated by RFLP similarity and coancestry coefficients. Pl. Breed., 117, 429-435.

ELLIS, R. H., SUMMERFIELD, R. J., ROBERTS, E. H. AND COOPER, J. H. 1989. Environmental control of flowering in barley (Hordeum vulgare). III. Analysis of potential vernalization responses, and methods of screening germplasm for sensitivity to photoperiod and temperature. Ann. Bot., 63, 687-704.

HAYES, P. M., LIU, B. H., KNAPP, S. J., CHEN, F., JONES, B., BLAKE, T. ET AL. 1993. Quantitative trait locus effects and environmental interaction in a sample of North American barley germ plasm. Theor. Appl. Genet., 87, 392-401.

KARSAI, I., MÉSZÁROS, K., HAYES, P. M. AND BEDÖ, Z. 1997. Effects of loci on chromosomes $2(2 \mathrm{H})$ and $7(5 \mathrm{H})$ on developmental patterns in barley (Hordeum vulgare L.) under different photoperiod regimes. Theor. Appl. Genet., 94, 612-618.
LAURIE, D. A., PRATCHETT, N., BEZANT, J. H. AND SNAPE, J. W. 1994. Genetic analysis of a photoperiod response gene on the short arm of chromosome $2(2 \mathrm{H})$ of Hordeum vulgare. Heredity, 72, 619-627.

LAURIE, D. A., PRATCHETT, N., BEZANT, J. H. AND SNAPE, J. W. 1995. RFLP mapping of five major genes and eight quantitative trait loci controlling flowering time in a winter $\times$ spring barley (Hordeum vulgare L.) cross. Genome, 38, 575-585.

MAPA 1997. Listas de Variedades Comerciales de Plantas. Año, 1997. Dirección General de Producciones y Mercados Agrícolas. Subdirección General de Semillas y Plantas de Vivero. Ministerio de Agricultura, Pesca y Alimentación, Spain.

PAKNIYAT, H., POWELL, W., BAIRD, E., HANDLEY, L. L., ROBINSON, D., SCRIMGEOUR, C. M. ET AL. 1997. AFLP variation in wild barley (Hordeum spontaneum $\mathrm{C}$. Koch) with reference to salt tolerance and associated ecogeography. Genome, 40, 332-341.

PAN, A., HAYeS, P. M., CHEN, F., CHEN, T. H. H., BlAKe, T., WRIGHT, S. ET AL. 1994. Genetic analysis of the components of winterhardiness in barley (Hordeum vulgare L.). Theor. Appl. Genet., 89, 900-910.

PAUll, J. G., CHALMERs, K. J., KARAKOUSIS, A., KRETSCHMER, J. M., MANNING, S. AND LANGRIDGE, P. 1998. Genetic diversity in Australian wheat varieties and breeding material based on RFLP data. Theor. Appl. Genet., 96, 435-446.

ROBERTS, E. H., SUMMERFIELD, R. J., COOPER, J. P. AND ELLIS, R. H. 1988. Environmental control of flowering in barley (Hordeum vulgare L.). I. Photoperiod limits to long-day responses, photoperiod-insensitive phases and effects of low temperature and short-day vernalization. Ann. Bot., 62, 127-144.

SAS INSTITUTE 1989. SAS/STAT User's Guide, Version 6, 4th edn, Vols 1 and 2. SAS Institute, Inc, Cary, NC.

TAKAHASHI, R. AND YASUDA, S. 1970. Genetics of earliness and growth habit in barley. In: Nilan, R. A. (ed.) Barley Genetics II, pp. 388-408. Washington State University, Pullman, WA.

TINKER, N. A., MATHER, D. E., ROSSNAGEL, B. G., KASHA, K. J., KLEINHOFS, A., HAYES, P. M. ET AL. 1996. Regions of the genome that affect agronomic performance in two-row barley. Crop Sci., 36, 1053-1062.

VAN OOSTERoM, E. J. AND ACEVEDo, E. 1992. Adaptation of barley (Hordeum vulgare L.) to harsh Mediterranean environments. III. Plant ideotype and grain yield. Euphytica, 62, 29-38.

VIRK, P. S., FORD-LLOYD, B. V., JACKSON, M. T., POONI, H.S., CLEMENO, T. P. AND NEWBURY, H. J. 1996. Predicting quantitative variation within rice germplasm using molecular markers. Heredity, 76, 296-304. 